\title{
Give yourself a write-up
}

ONE of the reasons that is regularly given for the decline in numbers of students wanting to study natural sciences and the concomitant growth in the numbers of those wanting to study, in particular, medicine and law, is that whilst medicine and the law is about people, science is about things and is therefore less human. Although the argument about the people-orientation of the law is one that is open to considerable debate, it is more important that the argument that science is about things is not allowed to pass unchallenged. For if science cannot present itself as a human activity, it not only loses potential bright students but it also positively encourages a science-for-people movement which at times seems only too glad to present science as practised by heartless technicians.

There have, of course, been a few who were prepared to say that science is only what its practitioners can agree amongst each other and thus does not reside ultimately in textbooks or learned journals. This puts science firmly in the realms of discussion, persuasion, criticism and dissent-very human activities. But scientists have rarely helped along this cause by leaving for others a very helpful record of their intellectual development, and if pressed have tended to regard scientific publications as adequate evidence.

At the same time, the historians of science seem to have increasingly fought shy of the twentieth century, not just because many of the major figures are still around (this, after all, has not inhibited historians in general) but also because to write on the recent past without putting it into a social, even ideological framework is somehow more difficult, although no less necessary. And social and ideological frameworks have become so much the fashion.

If there are a few very distinguished exceptions, such as Margaret Gowing both with her histories of atomic energy and her Contemporary Science Archives in Oxford, these only point to the need for more. If historians take too much refuge in Newton and sociologists in counting references, scientists should step into the breach themselves.

The web of personal relationships, ideas discarded, intellectual growth, differences of opinion in science is perhaps less fascinating to the general public than the revelations of a filmstar or even a vet. But it is certainly not worthless, and it can only really be relayed at first hand-by autobiography. Many published autobiographies are deceptive, self-serving or tedious but the accumulation of them helps a clear picture to emerge over the course of the years.

Most writers of autobiography have more than simply a desire that their world-view should be widely known; they are used to making a living by writing and view an autobiography as one more way of keeping the wolf from the door. The scientist does not live under the same sort of shadow and perhaps this is one of the reasons that scientific autobiography is rare. Another may well be that the skills, in recent years, of a Waugh, Russell or Muggeridge positively inhibit nonliterary characters from putting pen to paper. As a result, however, we are sadly deficient in any personal records of some of the scientific developments of the past fifty years-what people used to do, think, read, be influenced by, care about-and biography is not sufficient to remedy this (nor for that matter is scientific biography all that frequent at the sort of depth which helps one understand the human side of science)

Could not more scientists, including those with no particular eminence to their name, be persuaded to spend their last year or two in a tenured and secure post prior to retirement in getting down on paper-if only for it to sit in a university archives-what doing science was really like for them? This is something that the Royal Society could well stimulate, regardless of questions of literary merit. And who knows, there may even be a few more Watsons, Snows, Medawars out there. Well, one or two.

\section{The human breeding strategy}

Paul A. Colinvaux, Professor of Zoology at Ohio State University, takes issue with what Nature in a recent editorial called "the now widely accepted view" that high population growth is a consequence and not the cause of poverty

THE VIEW that high population growth is a consequence and not the cause of poverty is widely held by demographers, but it is not held by ecologists interested in breeding strategies of Darwinian species. The breeding stategy of the species Homo sapiens is comparable to that of many birds: a few large young are produced at a time, then fed and protected for a long period. This breeding strategy, which I have called "the large young gambit", confers fitness by yielding a high return of surviving and reproducing young for each unit of resource capital invested. The advantage of being given the large young gambit by natural selection can readily be seen by contrasting it with the breeding strategies of specjes which make very large num- bers of small eggs or seeds, what I call "the small egg gambit".

Small eggs, and the tiny young which hatch from them, are at high hazard, so that most of them die. Since every tiny corpse represents a unit of resource investment upon which there is no return, simple economic arguments show that fitness is likely to be greater when a small number of large young are reared and protected than when multitudes of tiny progeny are cast out to fend for themselves. The breeding strategy of people, therefore, is one that gives them great ability to 
maximise the return, particularly in circumstances of limited resources. It is a property they have in common with all followers of the large young gambit, with sparrows, antelopes, viviparous snakes, and great white sharks.

David Lack showed us 20 years ago that an essential requirement of the large young gambit is that the size of the family be closely gauged to the available resources. He produced good evidence that the clutch size of many birds is dependent on the food supply, the number of eggs laid varying from season to season. The original data can be found in his Natural Regulation of Animal Numbers, and there has since been overwhelming confirmation of his work. The mechanism deciding the clutch-size for a species following this gambit must ensure that the chosen clutch is not slightly too small for the available resources, or the genes for this mechanism will be removed from the population by natural selection favouring those genotypes which gave their possessors a slightly more ambitious clutch. But it must also ensure that the clutch is not too large, because an attempt to rear a family too numerous for the available resources puts all the progeny at hazard. The most fit individuals will be those which assess the food and other resources of their living space with the most precision.

Natural selection was undoubtedly alive and well when the breeding strategy of the Pleistocene populations of Homo was fashioned. Our ancestors were, therefore, adapted to make the best possible choice for the number of children in a family, "best" meaning the largest number for which there was a high probability of it being possible to rear them to maturity. There can be little doubt that the workings of intelligence gave people a skill in applying this breeding strategy which could not be equalled by birds, sharks, and the rest. It is against these Darwinian realities that there is scope for reappraisal of what we know of reproductive habit and taboo in primeval societies. Infanticide, for instance, appears to be, not a device for impeding population growth, but rather a device for increasing it. Infanticide is one of the mechanisms provided to human families by natural selection not to make the family too large for the available resources. It increases fitness. The pill, the diaphragm, and the lump of plastic perched in the uterus must be expected to work in the same way. Contraceptives ought to increase Darwinian fitness-a thought for those who ponder the failure of birth control schemes.

It appears that no human population has abandoned the Darwinian breeding strategy of our Pleistocene ancestors.
Every couple continues to choose the largest number of children it can afford to rear with a high expectation of success. The change we have made is to abandon many parameters of the old niche, replacing them with surrogates, and we have added to the niche many new parameters or alternatives. These changes in niche are well understood: farming instead of gathering; herding instead of hunting; concentrating in cities, which allows "agribusiness" and the bringing of food to people instead of people to food. These changes in niche are the real measure of the difference between people and the rest of Darwinian species, none of which can change their ways of life to suit their convenience as we can.

If a niche requires many resources, or allows many alternatives, an ecologist calls it "broad"; if a species is of stereotyped habit and highly specialised, its niche is called "narrow". Humanitarians refer to similar things when they talk of "riches" and "poverty". Rich people have large niches, poor people have small ones. It takes more resources (tangible and intangible) to provide niche space for a rich human couple than for a poor one.

But rich and poor alike retain their large-young breeding gambit. Each couple of both assesses the resources of its habitat in ways which have been programmed for them by natural selection from the times of remotest ancestors. We are conscious of these ways when we know that we love children. And our process of resourceassessment must always have taken into account the traditional ways of life. Even primeval people learned how to live from their parents and their parents' peers. Darwinian fitness (given by success at child-rearing) for these people must have been dependent on providing for each child the resources needed to let it grow up to live in the traditional way, for otherwise it would never be equipped to mate and rear children itself. A couple planning a family estimated, as it still does, the resources needed to raise a child to live as well as the parents lived. The number of children the couple chooses is the largest for which traditional resources can be provided. That people still behave so is the explanation for the fact that families in affluent countries tend to be smaller than families in poor countries, the so-called demographic transition. A well-off couple chooses the most children it can raise to well-off standards or even to slightly better standards, which is not likely to be many. The poor only have to provide for each child what is needed to raise it in poverty, which may allow for more children even when the actual resource base is less.

It is our experience with the demo- graphic transition which has allowed the claim to be made that high population growth is a consequence and not a cause of poverty. The element of truth which lies in the claim is the observed fact that families of the affluent tend to be smaller, for the good Darwinian reasons described above. But this is not to say that "high" population growth does not happen in the affluent (it can and does-see the history of the United States); it is merely to claim that the highest growth rates of the contemporary world are in poor nations. And it speaks not at all to the question of the cause of poverty itself. This too can be understood and predicted from a knowledge of the human habit of changing niche while keeping breeding strategy constant.

While people retain their excellent large-young gambit they can be expected to maximise the return, and this is true regardless of their standards of life. Increase in population with time will have a slightly higher value for th: poor, but this difference in value makes no difference to the size of the eventual population limit. Poverty is, of course, a relative value, and is better replaced in the interests of clear thinking by some measure of resources, or by the concept of niche-size itself, which G. E. Hutchinson showed us could in theory be quantified (see Cold Spring Harbor Symposium on Quantitative Biology). If riches and poverty are large niches and small, then they are properties of the size of population at all times except during rapid population growth.

Times of rapid growth are the exception because these must be times of excess resources. This is the explanation of affluence and rising numbers going together in the United States during the last century. There were for a time so many spare resources that almost unlimited choices for life were possible, giving rise to the most extravagant portions of the American Dream. But as numbers close on resources, as the population presses on the population limit, choice must go. Then, if the numbers continue to rise. the resource allocation per individual (its niche space) must decrease. People can accept changed niches, it is their unique quality. They continue to maximise the return even as the upper limit for their traditional way of life is reached. The next generation must respond by reducing the size of the niche so that the limit can be increased. But they, in turn, still maximise the return. All poverty is caused, in the long run, by the continued growth of population. The continued growth of population itself is caused by the combination of our excellent Darwinian breeding strategy and our ability to change the niche within wide limits. 